American Journal of Pharmaceutical Education 2017; 81 (2) Article 22.

\title{
VIEWPOINTS
}

\section{In Memoriam: George H. Cocolas, PhD}

\author{
Gayle A. Brazeau, PhD, ${ }^{\text {a,b }}$ Joseph T. DiPiro, PharmD ${ }^{\mathrm{c}, \mathrm{d}}$ \\ ${ }^{a}$ University of New England College of Pharmacy, Portland, Maine \\ ${ }^{\mathrm{b}}$ Editor, American Journal of Pharmaceutical Education, Alexandria, Virginia \\ ${ }^{\mathrm{c}}$ Virginia Commonwealth University, School of Pharmacy, Richmond, Virginia \\ ${ }^{\mathrm{d}}$ Editor emeritus, American Journal of Pharmaceutical Education, Alexandria, Virginia
}

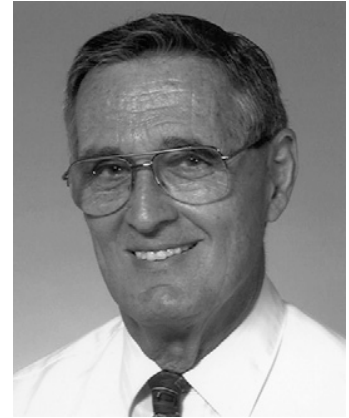

George H. Cocolas, $\mathrm{PhD}$

The pharmacy education academy lost a dear colleague and friend when Dr. George H. Cocolas died at the age of 87 on December 19, 2016. Dr. Cocolas served as the fifth editor of the American Journal of Pharmaceutical Education (AJPE) from 1980-2002. He was a key figure in establishing the international reputation of the Journal and advancing its critical role in modern pharmacy education. George, along with Erie, his wife of 63 years, and several other Cocolas family members, ensured that $A J P E$ was published and distributed to the members of the academy. ${ }^{1}$

Dr. Cocolas graduated in pharmacy from the University of Connecticut in 1952 and earned his $\mathrm{PhD}$ in medicinal chemistry in 1956 from the University of North Carolina, Chapel Hill (UNC). He had a distinguished career at UNC from 1958 to 1999 as professor of medicinal chemistry, chair of the Division of Medicinal Chemistry, and associate dean of the school of pharmacy and director of admissions. He positively influenced the lives of more than 6,000 students in his years at UNC. He also impacted our careers and the careers of many pharmacy academicians through his volunteer activities for the American Association of Colleges of Pharmacy (AACP), ranging from contributions to the Medicinal Chemistry section, the Resolutions Committee, the Research and Graduate
Affairs Committee, and the Pharmacy College Admissions Test Advisory Committee. He was elected AACP Honorary President in 2003. Dr. Cocolas also was involved with the American Pharmacists Association Academy of Pharmaceutical Sciences as the chair of the Medicinal Chemistry Section and as chair of the American Chemical Society Medicinal Chemistry Symposium in 1986.

Those of us who were fortunate to know George will always remember him as a true gentleman and scholar, with a warm, generous personality and grace combined with an infectious smile. He would always find the time to actively listen and mentor others in large group meetings or in one-on-one conversations. In his role as AJPE Editor, he was known for his diplomacy and compassion in mentoring authors from submission to publication of their papers. Many of us can remember firsthand how George was able to help us achieve our first publication in $A J P E$. His words of encouragement and guidance were so essential to many new authors who had little experience publishing in an educational journal. His contributions to AJPE during his 22-year tenure as editor will long be remembered.

For many of us who knew both George and Erie, it was always wonderful to share an evening together with these two special people. One could instantly feel their love for each other and their passion for all that is pharmacy education and the Journal. We looked forward to seeing them at professional meetings because they would always remember names and would want to know how things were going in school and at home. It made you feel like you were with a caring family member. We will always appreciate what George contributed to $A J P E$ and pharmacy education. He will truly be missed.

\section{REFERENCES}

1. Furman S, Campbell W. Dedication: George H. Cocolas, Editor, American Journal of Pharmaceutical Education, 1980-2002. Am J Pharm Educ. 2003:67(1):Article 1. 